BMJ Nutrition,

Prevention \& Health

\title{
Hidden curriculum within nutrition education in medical schools
}

\author{
Stephen Martin, ${ }^{1}$ Elizabeth Sturgiss, ${ }^{1,2}$ Kirsty Douglas, ${ }^{1}$ Lauren Ball (i) ${ }^{3,4}$
}

\begin{abstract}
To cite: Martin S, Sturgiss E, Douglas $\mathrm{K}$, et al. Hidden curriculum within nutrition education in medical schools. BMJ Nutrition, Prevention \& Health 2020;3:e000059. doi:10.1136/ bmjnph-2019-000059

${ }^{1}$ Academic Unit of General Practice, Australian National University Medical School, College of Health and Medicine, Australian National University, Canberra, Australian Capital Territory, Australia

${ }^{2}$ Department of General Practice, Monash University, Melbourne, Victoria, Australia

${ }^{3}$ Menzies Health Institute Queensland, Griffith University, Gold Coast, Queensland, Australia

${ }^{4}$ NNEdPro Global Centre for Nutrition and Health, Cambridge, UK
\end{abstract}

Correspondence to Associate Professor Lauren Ball, Menzies Health Institute Queensland, Griffith University, Gold Coast, QLD 4222, Australia; I.ball@griffith.edu.au

Received 27 October 2019 Revised 27 November 2019 Accepted 11 December 2019 Published Online First 5 February 2020

Check for updates

(c) Author(s) (or their employer(s)) 2020. Re-use permitted under CC BY-NC. No commercial re-use. See rights and permissions. Published by BMJ.

\begin{abstract}
Introduction Previous attempts to enhance medical nutrition education have typically focussed on students' acquiring nutrition knowledge or skills. Given that medical training uses an apprenticeship model of training, surprisingly few studies have explored the 'hidden curriculum' that students experience regarding expectations of behaviour, roles and responsibilities regarding nutrition. This study explored medical students' perceptions and experiences regarding medical nutrition education, focussing on the context in which nutrition teaching has been provided, the presented place of nutrition within medicine and their subsequent views on their role in providing nutrition care.
\end{abstract}

Methods Individual semi-structured qualitative interviews were conducted with 14 postgraduate medical students at different stages of their medical degree in Australia. The interviews were conducted using case studies followed by interview questions. Data were audio recorded, transcribed, coded and then underwent inductive thematic analysis.

Results Three themes were discovered (i) Valuing nutrition in the medical management of patients whereby students perceived nutrition to be a foundational and central component of ideal medical management for patients, particularly those with chronic disease; (ii) Fluctuating emphasis on nutrition which showed that students experienced diversity in the importance placed on nutrition by others and (iii) Working with others whereby students expressed their understanding of their role in nutrition and the roles of team members such as dietitians. Conclusion To enhance medical nutrition education, consideration needs to extend beyond counting dedicated teaching hours and mapping nutrition content, to a more contextual understanding of the situated learning that occurs for medical students.

\section{INTRODUCTION}

The problem of inadequate nutrition education during medical training has been acknowledged for over five decades,${ }^{1-5}$ with minimal clear gains made in recent years. ${ }^{6}$ Nutrition is a key component of good health ${ }^{7}$ and nutrition care is recommended as the first-line action for preventing and managing chronic disease. ${ }^{8}$ Doctors report lacking the training and confidence in providing advice around nutrition, ${ }^{10-13}$ but patients regard nutrition as part of the ideal care they receive from doctors. ${ }^{14}$ As a result, less than
What this paper adds?

Medical students perceive nutrition to be a foundational and central component of ideal medical management for patients

- Medical students have variable experiences in the importance placed on nutrition by educators

- Medical students value their future role in supporting healthy eating, and the role of other professionals, including dietitians

a third of patients with poor diet remember ever discussing nutrition with a doctor in the past, ${ }^{15}$ warranting strategies to support nutrition being integrated into routine medical care.

There have been repeated calls to improve the focus and quality of nutrition education at medical school and a wide range of interventions have been trialled to address this issue. ${ }^{16}$ Most interventions report modest benefit from focussing on the acquisition of nutrition knowledge to modify students' dietary behaviours and intention to provide nutrition care in the future. ${ }^{17-19}$ Some approaches to improving nutrition in medical education engage clinical experts who are not doctors, such as biochemists ${ }^{20}$ or dietitians. ${ }^{21}$ Other studies have examined proxies for nutrition education, such as guidelines for medical nutrition education ${ }^{22}$ and the content and number of hours dedicated to nutrition in curricula. ${ }^{20}$ However, few studies acknowledge the complex learning environment of medical training that involves strong elements of enculturation and normative behaviour. ${ }^{23}$ In line with this limitation, the degree to which medical students place an emphasis on nutrition during medical training has been identified as an important ongoing research question in the field. ${ }^{24}$

Medical training has been recognised as a form of 'situated learning', where students gradually increase legitimate participation through interactions with experts, leading to the development of a professional identity. ${ }^{25}$ In this apprenticeship model of medical 
training, learners are exposed to real-world situations to learn from experts in the field. ${ }^{26}$ It is increasingly recognised that as well as the explicit curriculum, medical students learn the 'hidden curriculum' of medicine that teaches them about the expectations of behaviour, professionalism, roles and responsibilities. ${ }^{27}$ The hidden curriculum is now recognised as a powerful driver of doctor behaviour and professional responsibility. ${ }^{27}$

It is unclear how the hidden curriculum influences nutrition education for medical students in the apprenticeship model of training. To address this gap, the aim of this study was to explore medical students' perceptions and experiences regarding medical nutrition education, focussing on the context in which nutrition teaching has been provided, the presented place of nutrition within medicine and their subsequent views on their role in providing nutrition care.

\section{METHODS}

\section{Design and study setting}

This was a qualitative study in which semi-structured interviews lasting 30 to $60 \mathrm{~min}$ were conducted with students who were at different stages of their medical degree. Participants were recruited from one postgraduate medical programme in Australia. In Australia, medical schools offer undergraduate or postgraduate programme that take 4 to 6 years. The curriculum of each medical school must comply with the Standards for Assessment and Accreditation of Primary Medical Programs by the Australian Medical Council. Australia has an externally visible basic nutrition curriculum guideline (Deakin University 2013) but no mandatory enforcement. This situation aligns with several other countries including the USA, Canada and New Zealand (Crowley et al 2015).

\section{Participants and recruitment}

All students currently studying in the institution's medical programme were eligible to participate. Because we wanted to investigate the context in which students' experienced nutrition education and impact this had on students' views of nutrition, we sought to include a diverse sample of students from each year of the 4-year programme. We used maximum variation sampling to recruit a diverse sample of students from each year of the 4-year programme. We purposefully recruited via public messages on social media and local posters in order to reach students outside of their structured learning activities. Recruitment stopped when theme saturation in the data was reached, as described below. Each participant was provided a $\$ 20$ coffee card in appreciation of their time.

\section{Interviews}

Individual interviews were conducted using case studies followed by semi-structured interview questions. Students were initially blinded to the nutrition focus of the study and were told that our interest was their ideas around the general management of chronic disease. Students were provided with two clinical vignettes involving a patient

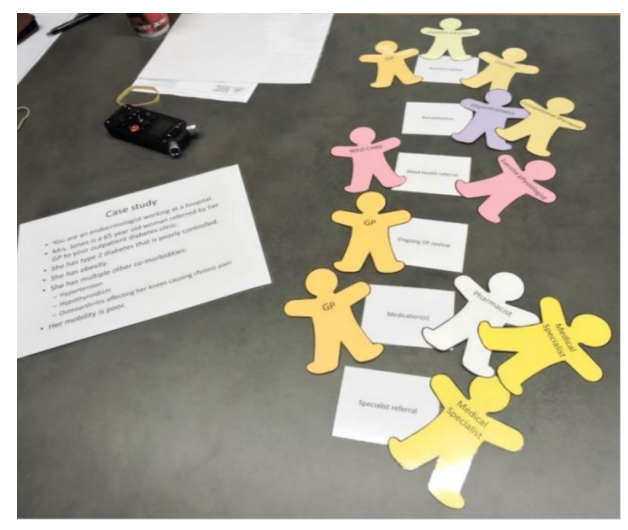

Figure 1 Endocrine specialist case study in chronic disease management, arrangement of management cards and people involved in care, participant 9 .

with chronic disease and asked to role play as an endocrinologist in the first case, and a family physician in the second. We stated that we were examining students' clinical reasoning and how they perceived the 'real job' of being a doctor at their stage of medical training. Students were given cut-out figures to prioritise management options and indicate what type of practitioner should take the lead for different aspects of the patient management. We photographed how the students' laid the cards out for their management plan (figure 1).

The students were then told that we were most interested in nutrition and medical practice. Students were asked semi-structured questions about their personal beliefs about nutrition, their experience of nutrition education and what they had observed so far in clinical practice. We asked the participants to recall specific instances of nutrition teaching in their course. To facilitate this question, we used a sheet of keywords to prompt reflections on the curriculum. We also used cartoons of faces with different expressions to explore participants' feelings about nutrition education and clinical practice.

\section{Data collection and analysis}

All interviews were conducted by SM, a recent graduate of the medical school who held an academic training post in general practice. SM was also involved in teaching third year medical students about child and community health and was an academic advisor to a small group of students, one of whom was a participant. This student initiated participation after seeing a recruitment poster and was aware that SM would be the interviewer.

The interviews were audio recorded, transcribed and de-identified. Two researchers independently coded the interview transcripts (SM and ES) using NVivo to assist with organising the coding and to extract themes. The study was informed by the process of inductive thematic analysis. ${ }^{28}$ The first three interviews were conducted, coded by two reviewers and discussed. After every interview a discussion was had about codes and themes that were raised in the interview. We continued interviewing 
participants until we had two interviews where no new ideas or concepts were raised by the interviewee.

\section{RESULTS}

We interviewed 14 medical students, eight females and six males. Five participants were aged under 25 years and nine were aged between 25 to 29 years. Six participants were in the first 2 years of the 4-year postgraduate medical programme and eight participants were in the last 2years. Three themes were discovered inductively; (i) Valuing nutrition in the medical management of patients whereby students perceived nutrition to be a foundational and central component of ideal medical management for patients, particularly those with chronic disease; (ii) Fluctuating emphasis on nutrition which showed that students experienced diversity in the importance placed on nutrition by others and (iii) Working with others whereby students expressed their understanding of their role in nutrition and the roles of team members such as dietitians.

\section{Valuing nutrition in the medical management of patients}

All participants proactively raised the topic of nutrition in the case studies discussed during the interviews. Without exception, participants prioritised nutrition in the hypothetical management of the case studies by placing the card with 'nutrition advice' very high on the management list.

Being in hospital and seeing the long-term consequences of poor nutrition and the impact that has on patient's health and the multi health impact of it, multi organ impact of poor nutrition. I think that's why it's really important. (Male, Year 4)

Several participants stated health providers that could provide nutrition care to the patients in the case studies, including family physicians, dietitians and diabetes educators.

The Dietitians were just as equal a member of the team, as the Consultant, as the Physios, as the Dialysis Nurses. It was all, sort of, part of that team structure and the Nutritionists and the Dietitians had a big role in that because as soon as the patients left the hospital, diet it one of the big things that sort of sends people crashing down and so that was really important for them. (Female, Year 4)

Participants described several factors they considered when prioritising nutrition care as a doctor. Nutrition was deemed as very important for chronic conditions (as opposed to highly acute conditions), managed in primary care (as opposed to tertiary care), by family physicians (as opposed to specialist doctors).

I think at least being aware of the guidelines and the latest recommendations are really important. You don't have to be an expert in nutrition but you should have an understanding because patients often ask. (Male, Year 4)

They should have some knowledge about it (nutrition), absolutely the generalists and GPs. (Male, Year 4)

\section{Fluctuating emphasis on nutrition by role models}

The high priority that participants placed on nutrition in the case studies contrasted with their experiences of learning about nutrition during medical training. Participants reported diversity in their experiences of how nutrition care was taught and modelled to them during their medical training. Several participants described seeing doctors in a range of settings explicitly incorporate nutrition care into patient management plans, show enthusiasm for nutrition care and work effectively alongside allied health practitioners. Other participants described seeing supervising doctors delegate responsibility for nutrition care to other practitioners, which was interpreted as devaluing nutrition. Many participants also described situations where they observed clinicians having a dismissive attitude towards nutrition care and stated it was unimportant to them.

... a lot of them (educators) don't seem to focus much on nutritional care and I think very few doctors have actually demonstrated to me that they have a good understanding of nutrition at least to an extent that I think we probably should. (Female, Year 4)

Presenting a long case to the surgeon, it's like 'Yeah you can skip over this part (about nutrition), I don't really care'. (Male, Year 4)

I haven't experienced any GPs giving out nutrition advice just because they could. They've only really done it when either the patient has asked or they've been overweight. (Female, Year 3)

Several participants commented that nutrition was devalued by educators relative to other curriculum content. Some participants reported that their educators described nutrition as an assumed and inherent knowledge base that should have been obtained from foundational experiences prior to medical school. Furthermore, nutrition was described as rarely discussed or assessed and was therefore not a major focus on students' learning activities. Some students noted that assessments focussed on core medical skills involving basic medical science, clinical reasoning, diagnosis and disease-based management and nutrition was not considered by their educators to be a part of this core.

Nutrition (is) in that background, talked about as a thing that's important but never really as important as everything else that's going on. (Male, Year 4)

Very few participants were able to recall any specific nutrition education sessions they had participated in during medical training. In the second year of the medical programme, there is a compulsory assignment where students keep a diary of all food and drinks consumed for 3 days, which is then analysed using computer software to determine the content of specific nutrients. However, 
the assignment does not contribute to the grading of the subject. Participants reported confusion and frustration about why the assignment was needed, citing that it was not assessable or part of their ideal role in practice.

It (the assignment) was just sort of 'You should probably know this'... peripheral was a good word as well because most of us are just focussing on physiology and the things that we know will come up in the exam. (Female, Year 2)

\section{Working with others}

Participants consistently reported that providing nutrition care was a core skill for doctors. However, this statement was often qualified by describing that doctors are often time poor and have multiple other responsibilities that limit their ability to deliver comprehensive nutrition care to all patients who need it. Students valued the role of nutrition care for patients and recognised the importance that it has in planning chronic disease management. However, many participants felt that the realities of providing medical care under time pressure meant that doctors should focus on the coordinating nutrition care to be delivered from dietitians.

My understanding and experience with my clinical rotation is that the family physician is the one who is intrinsically involved with the overarching responsibility of what, who goes where and what they get from who. (Male, Year 4)

I think at least being aware of the guidelines and the latest recommendations are really important. You don't have to be an expert in nutrition but you should have an understanding because patients often ask. (Male, Year 4)

All participants stated that dietitians are well trained to provide nutrition care to patients. Dietitians were considered to have benefitted from their specific training in nutrition and they also have the time to comprehensively address a patient's nutrition status and provide specific expert advice. Participants across all 4 years of the medical school felt that doctors provide limited advice and dietitians provide more effective nutrition care. In this case the student sees the doctor passing responsibility for nutrition care to others and may not appreciate the constraints on the doctor's time or the norms of interaction between subspecialists in a tertiary hospital that dictate the delegation of care out of professional courtesy. Several contrasts were made between the depth and breadth of knowledge required by doctors with the expertise of dietitians who were seen as the experts in nutrition.

I mean the dietitian, they do a 3 year, 4 year course in it. So, I would trust them to know what they're doing. (Female, Year 3)

I would probably refer them to a dietitian probably because the dietitian, that's literally their job, to do, like that's what they're specialised in doing so they'd probably be more helpful for them to get someone like that. (Female, Year 1)

\section{DISCUSSION}

This is the first study to identify the hidden curriculum within nutrition education in medical schools. The findings are timely given the repeated calls to improve the focus and quality of nutrition education at medical school and a wide range of interventions have been trialled to address this issue. ${ }^{16}$ Further, this is a novel study as most previous initiatives have focussed on overt strategies to increase nutrition knowledge and subsequently intentions to provide nutrition care to patients in the future. ${ }^{17-19} 29$ This is one of the only studies in nutrition to acknowledge the complex learning environment of medical training that involves strong elements of enculturation and normative behaviour. ${ }^{23}$

The postgraduate medical students in this study were clearly aware of the important role of nutrition for patients who are managing chronic disease and could articulate this during brief case studies in both community and hospital settings. This finding has not occurred in many other studies, where students report suboptimal attitudes about nutrition and are not always aware of how it can impact on patients' management of chronic disease and other conditions. ${ }^{2030}{ }^{31}$ It is therefore possible that the students in this study differed to other studies in their previous experience or that the design of this study enabled students to express their favourable views. The students' regard for nutrition was in contrast to their experience of nutrition teaching in their medical course where they felt nutrition was not a valued part of the teaching. This finding is directly in line with other literature investigating medical students, interns, junior doctors and residents, ${ }^{31-33}$ suggesting that further enhancements of nutrition in medical education is warranted from the perspective of medical students.

The students in this study reported variable experiences about learning nutrition concepts and watching supervisors and educators integrate nutrition into care. This variability may be due to differences in the backgrounds of clinicians and their use of nutrition in clinical practice, such as general physicians, gastroenterologists and dietitians. Although the medical students in this study had difficulty recalling specific lectures and assignments around nutrition, they were taught by dietitians which is emerging as a novel and appropriate addition to teaching teams in medicine. ${ }^{21}$ However, the medical course is very full, with a real discriminating pragmatism evident among the study participants in their choice of material to study. Nutrition content was seen as seldom examined and 'low yield', and was perceived by some students to be easily answerable from simple first principles, which has also been shown in other studies. ${ }^{21} 3435$

Our study suggests that to enhance medical nutrition education, consideration needs to extend beyond counting hours and mapping nutrition content, to a more contextual understanding of the situated learning that 
occurs for medical students. The apprenticeship-based model of medical training makes the role of the expert doctor-teacher central to enhancing the doctor role in nutrition care for patients. The as yet unrecognised, key role of the doctor-teacher is a new target for nutrition education. If upskilling of doctor-teachers is effective, it could lead to an increase in the positive role-modelling seen by medical students during their placements. Future strategies to improve medical nutrition education should include consideration of professional role models and their messaging around the importance of nutrition and how to integrate this into routine, usual care ${ }^{36}$ All doctors have a requirement to take part in ongoing professional development and these are avenues that could be used to upskill doctor-teachers in nutrition care.

Our study had a number of strengths including a theory-informed approach to data collection and analysis, plus the construction of the interview to capture information using the gamified approach. Coding was also done in an iterative and team-based approach to ensure the requirements for data saturation were appropriately met. ${ }^{28}$ Our sample was taken from one medical school and it could be further strengthened by examining this phenomenon in other medical schools. We saw a marked difference between the importance students placed on nutrition care for patients and the perceptions they had of their senior colleagues and it is possible that a change in societal attitudes towards nutrition was an influence. This could be explored by studying the perceptions, attitudes and understanding of teaching faculty and clinical supervisors towards nutrition care.

This detailed exploration of the perceptions of postgraduate medical students towards nutrition education highlights the need for contextual, theoretically informed approaches to improving nutrition education in medical schools. Increasing the number of hours spent on nutrition and improving the quality of content may not be enough to effectively change the future practice of doctors. ${ }^{31}$ Careful consideration should be given to the situated learning that occurs in medical schools where the apprenticeship model influences the perception students have about their future role. The hidden curriculum is the implicit teaching that occurs in this process and informs new doctors on their professional responsibilities and behaviours. Future nutrition education in medical schools should emphasise the role of doctor-teachers as role models and continuing professional development for faculty and clinical supervisors is likely to assist in improving the overall experience and learning of medical students.

Correction notice The article has been corrected since it was published online. The license type of the article has been updated to CC BY-NC.

\section{Twitter Lauren Ball @laurenball01}

Acknowledgements The authors would like to thank the medical students for their time and consideration in providing their opinions and experiences for this study. Also, they are thankful to BMJ Nutrition, Prevention \& Health for the open fee waiver due to Lauren Ball being a member of the NNEdPro Virtual Core team and on the BMJ Nutrition, Prevention \& Health Management Committee.
Contributors All authors participated in the design and conceptualisation of the project. SM conducted data collection, supported by ES, KD and LB. SM and ES had full access to all the data in the study and takes responsibility for the integrity of the data and the accuracy of the data analysis. All authors participated in the analysis and interpretation of the data and writing of the manuscript.

Funding This research project was supported by the Royal Australian College of General Practitioners with funding from the Australian Government under the Australian General Practice Training programme.

Disclaimer The funder had no role in the design, conduct, analysis or publication of the work. SM and ES had full access to all the data in the study and takes responsibility for the integrity of the data and the accuracy of the data analysis.

Competing interests None declared.

Patient consent for publication Not required.

Ethics approval The project was approved by the institutional Human Research Ethics Committee.

Provenance and peer review Not commissioned; externally peer reviewed.

Data availability statement Data are available upon reasonable request. Please email l.ball@griffith.edu.au for data requests.

Open access This is an open access article distributed in accordance with the Creative Commons Attribution Non Commercial (CC BY-NC 4.0) license, which permits others to distribute, remix, adapt, build upon this work non-commercially, and license their derivative works on different terms, provided the original work is properly cited, appropriate credit is given, any changes made indicated, and the use is non-commercial. See: http://creativecommons.org/licenses/by-nc/4.0/.

ORCID iD

Lauren Ball http://orcid.org/0000-0002-5394-0931

\section{REFERENCES}

1 Council on Foods and Nutrition. Nutrition teaching in medial school. JAMA 1963;183:955-7.

2 United Kingdom Department of Health and Social Security. Inequalities in health: report of a research Working Group (black report. London, 1980.

3 Kolasa KM. "Images" of nutrition in medical education and primary care. Am J Clin Nutr 2001;73:1006-9.

4 Raman M, Violato C, Coderre S. How much do gastroenterology fellows know about nutrition? J Clin Gastroenterol 2009;43:559-64.

5 Vetter ML, Herring SJ, Sood M, et al. What do resident physicians know about nutrition? An evaluation of attitudes, self-perceived proficiency and knowledge. J Am Coll Nutr 2008;27:287-98.

6 Gramlich LM, Olstad DL, Nasser R, et al. Medical students' perceptions of nutrition education in Canadian universities. Appl Physiol Nutr Metab 2010;35:336-43.

7 World Health Organization. WHO technical report series: diet, nutrition, and the prevention of chronic diseases. Geneva, 2003.

8 Diabetes United Kingdom. Evidence based nutrition guidelines for the prevention and management of diabetes. London, 2011.

9 Franz MJ, Boucher JL, Evert AB. Evidence-Based diabetes nutrition therapy recommendations are effective: the key is individualization. Diabetes Metab Syndr Obes 2014;7:65-72.

10 Ball L, Hughes R, Leveritt M. Health professionals' views of the effectiveness of nutrition care in general practice setting. Nutr Diet 2013;70:35-41.

11 Ball LE, Desbrow B, Yelland M, et al. Direct observation of the nutrition care practices of Australian general practitioners. J Prim Health Care 2014;6:143-7.

12 Crowley J, Ball L, McGill A-T, et al. General practitioners' views on providing nutrition care to patients with chronic disease: a focus group study. J Prim Health Care 2016;8:357-64.

13 Crowley J, Ball L, Han DY, et al. Doctors' attitudes and confidence towards providing nutrition care in practice: comparison of new Zealand medical students, general practice registrars and general practitioners. J Prim Health Care 2015;7:244-350.

14 Ball L, Hughes R, Desbrow B, et al. Patients' perceptions of nutrition care provided by general practitioners: focus on type 2 diabetes. Fam Pract 2012;29:719-25.

15 Harris MF, Fanaian M, Jayasinghe UW, et al. What predicts patientreported GP management of smoking, nutrition, alcohol, physical activity and weight? Aust J Prim Health 2012;18:123-8.

16 Dang TM, Maggio LA. Supporting the call to action: a review of nutrition educational interventions in the health professions literature and MedEdPORTAL. Acad Med 2017;92:403-16. 
17 Vargas EJ, Zelis R. Integrating nutrition education into the cardiovascular curriculum changes eating habits of second-year medical students. J Clin Lipidol 2014;8:199-205.

18 Crowley J, Ball L, Leveritt MD, et al. Impact of an undergraduate course on medical students' self-perceived nutrition intake and selfefficacy to improve their health behaviours and counselling practices. J Prim Health Care 2014;6:101-7.

19 Armstrong EG, Koffman RG. Enhancing nutrition education through faculty development: from workshops to web sites. Am J Clin Nutr 2000;72:877S-81.

20 Adams KM, Kohlmeier M, Zeisel SH. Nutrition education in U.S. medical schools: latest update of a national survey. Acad Med 2010;85:1537-42.

21 Burch E, Crowley J, Laur C, et al. Dietitians' perspectives on teaching nutrition to medical students. J Am Coll Nutr 2017;36:415-21.

22 Crowley J, Ball L, Laur C, et al. Nutrition guidelines for undergraduate medical curricula: a six-country comparison. Adv Med Educ Pract 2015;6:127-33.

23 Hafferty FW. Beyond curriculum reform: confronting medicine's hidden curriculum. Acad Med 1998;73:403-7.

24 Ball L, Barnes K, Laur C, et al. Setting priorities for research in medical nutrition education: an international approach. BMJ Open 2016;6:e013241.

25 Hafferty FW, Franks R. The hidden curriculum, ethics teaching, and the structure of medical education. Acad Med 1994;69:861-71.

26 Yardley S, Teunissen PW, Dornan T. Experiential learning: AMEE guide No. 63. Med Teach 2012;34:e102-15.

27 Rajput V, Mookerjee AL, Cagande C. The contemporary hidden curriculum in medical education. MedEdPublish 2017;6.
28 Braun V, Clarke V. Using thematic analysis in psychology. Qual Res Psychol 2006;3:77-101.

29 Weinsier RL, Boker JR, Feldman EB, et al. Nutrition knowledge of senior medical students: a collaborative study of southeastern medical schools. Am J Clin Nutr 1986;43:959-68.

30 Mihalynuk TV, Scott CS, Coombs JB. Self-reported nutrition proficiency is positively correlated with the perceived quality of nutrition training of family physicians in Washington state. Am J Clin Nutr 2003;77:1330-6.

31 Crowley J, Hiddink GJ, Ball L. Are we enabling food to be thy medicine? A systematic review of nutrition education in medical school. Lancet Planet Health. In Press 2019.

32 Crowley J, Ball L, Han DY, et al. Doctors' attitudes and confidence towards providing nutrition care in practice: comparison of new Zealand medical students, general practice registrars and genera practitioners. J Prim Health Care 2015;7:244-50.

33 Walsh CO, Ziniel SI, Delichatsios HK, et al. Nutrition attitudes and knowledge in medical students after completion of an integrated nutrition curriculum compared to a dedicated nutrition curriculum: a quasi-experimental study. BMC Med Educ 2011;11:58.

34 Aspry KE, Van Horn L, Carson JAS, et al. Medical nutrition education, training, and competencies to advance guideline-based diet counseling by physicians: a science Advisory from the American heart association. Circulation 2018;137:e821-41.

35 Devries S, Willett W, Bonow RO. Nutrition education in medical school, residency training, and practice. JAMA 2019;321:1351-2.

36 Heimburger DC. Training and certifying physician nutrition specialists: the American Board of physician nutrition specialists (ABPNS). Am J Clin Nutr 2006;83:985S-7. 